\title{
The development of winter hardiness of pine and spruce seedlings in a simulated acid rain experiment
}

\author{
J. Reinikainen and S. Huttunen
}

Department of Botany, University of Oulu, SF-90570 Oulu, Finland

Introduction

The effects of acidified rainwater on the hardiness level perceivable in the ultrastructure of needles of conifer seedlings were examined during autumn and winter 1986-87.

\section{Materials and Methods}

One and 2 yr old Scots pine (Pinus sylvestris) and Norway spruce (Picea abies) seedlings from several provenances had been irrigated with artificially acidified rain $\left(\mathrm{H}_{2} \mathrm{SO}_{4}: \mathrm{HNO}_{3}, 2: 1\right)$ for 7 wk during the hardening time in the previous autumn. In the experiment performed at the University of Oulu, the seedlings investigated comprised samples treated with $\mathrm{pH} 3, \mathrm{pH} 4$ and clean ( $\mathrm{pH}$ about 7) water, in addition to a dry control, with samples of each group from 2 different provenances. The development of the hardiness level was followed by making light and electron microscope observations of the mesophyll tissue of the current year's needles. Sampling was done about once a month from August until April. The $0.5 \mathrm{~mm}$ thick needle cuttings were fixed with glutaraldehyde and $\mathrm{OsO}_{4}$ in 0.05 or $0.1 \mathrm{M}$ phosphate buffer and, after fixation, the needle sections were dehydrated in an alcohol series and embedded in Ladd's epon.
Results

The hardening of the seedlings had already begun in mid-August, with decreasing numbers of starch grains and chloroplasts moving towards cell corners (Fig. 1). The needles of the northernmost provenances of spruce seedlings lost their starch grains

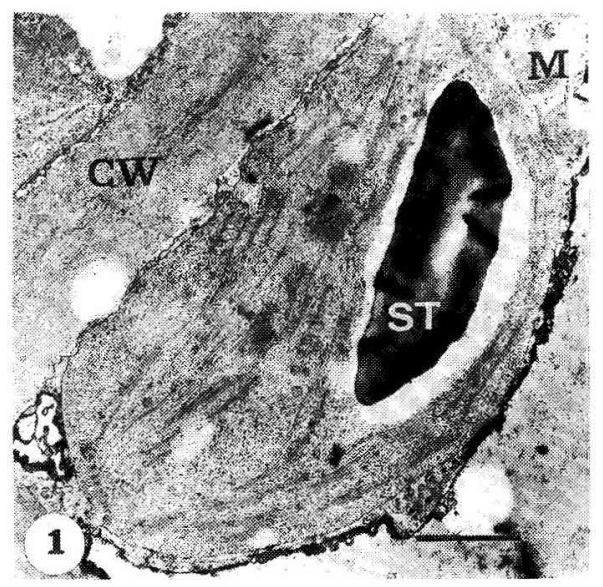

Fig. 1. August, a clean water-treated needle from a southern spruce provenance. Small starch grain (ST) indicates the beginning of the hardening period. $\mathrm{CW}=$ cell wall, $\mathrm{M}=$ mitochondria. bar $=1 \mu \mathrm{m}$. 


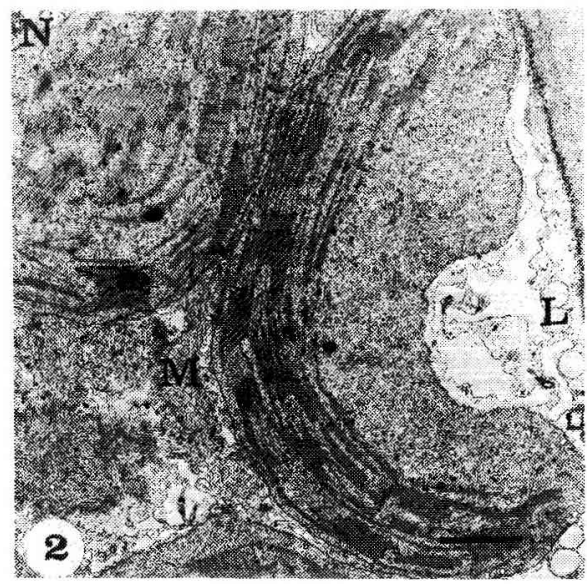

Fig. 2. September, a pH 3-treated needle from a southern spruce provenance. The cytoplasm membranes appear net-like and small lipid droplets (L) accumulate. $\mathrm{N}=$ nucleus, $\mathrm{M}=$ mitochondria. bar = $1 \mu \mathrm{m}$.

earlier than the southernmost seedlings, whereas in pine seedlings no great differences could be seen in this respect. In September, the cytoplasm became netlike upon the increase of the endoplasmic reticulum (Fig. 2). During August-October, many small vacuoles containing granular material developed in the cytoplasm.

Myelin-like membranous formations in the cytoplasm became abundant during the winter period (Fig. 3). As of September, small, single-membrane fragments were seen in the membrane-free areas of the chloroplasts. The highest incidence of these was noted in March-April, when also large, whorl-like membranous structures were seen in abundance in chloroplast stromata. Chloroplast division was greatest in September-October, but throughout the winter some dividing chloroplasts could be seen. The mesophyll cells started to revert from the hardened to the unhardened state in March-April, when the starch grains again appeared (Fig. 4). The exposure to acid rain did not significantly alfect the ultrastructure of the needles during the first winter.

\section{Discussion and Conclusion}

The deleterious effects of air pollutants on the cold tolerance of conifers have been reported quite recently by several authors (e.g., Davison and Barnes, 1986; FreerSmith and Mansfield, 1987). However, the effects of acid rain on conifer seedlings could not be seen in the hardening process after 2 months' exposure. Our results clarify the development of cold hardiness at the ultrastructural level. The hardening began in mid-August and the maximum

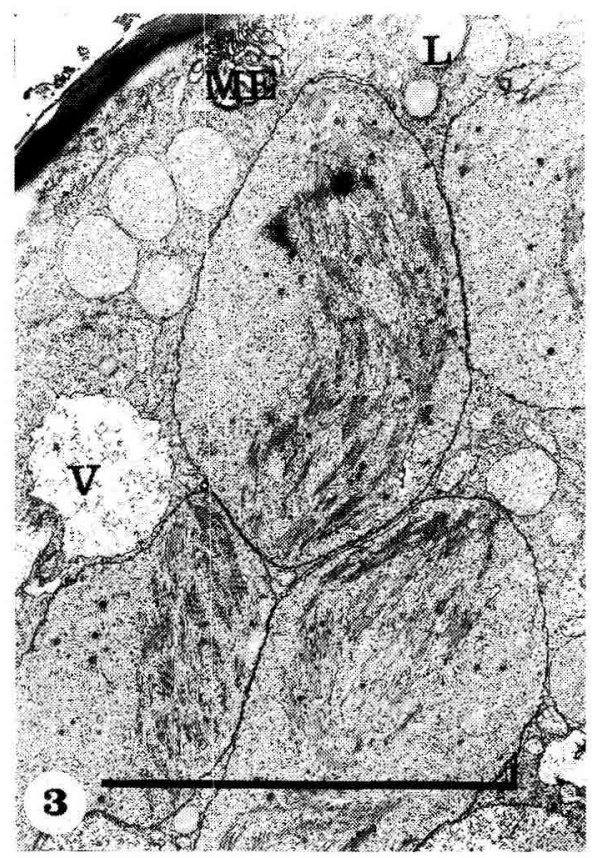

Fig. 3. February, a clean water-treated needle from a northern pine provenance. In a fully hardened state small vacuoles (V) myelin-like membrane structures (ME) and lipid droplets (L) are seen in the cytoplasm. bar $=1 \mu \mathrm{m}$. 


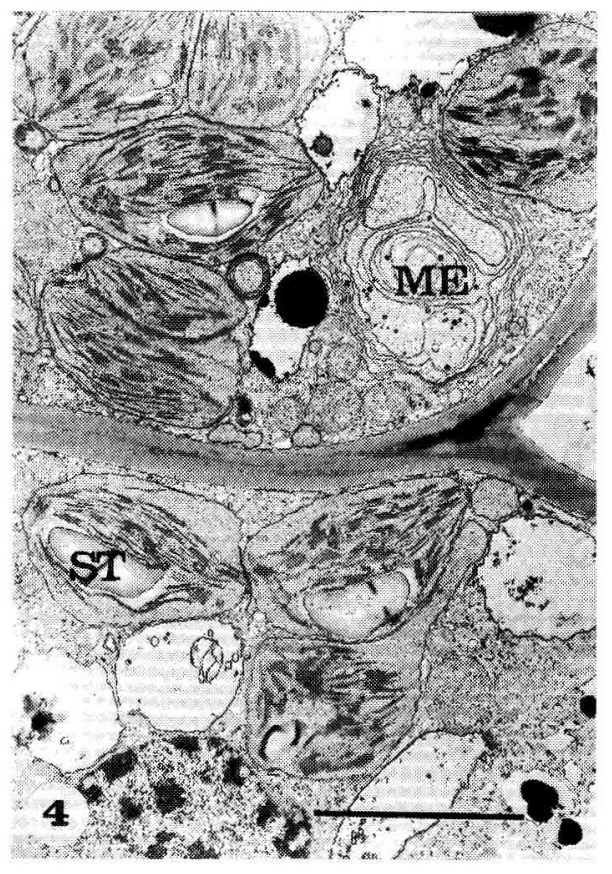

Fig. 4. April, a clean water-treated needle from a southern spruce provenance. Rounded membranes are seen in abundance in the cytoplasm (ME). Starch (ST) has again accumulated in the chloroplasts. bar $=5 \mu \mathrm{m}$.

hardiness level was reached in December-February. The changes towards springtime started in March-April, when considerable amounts of starch were seen to accumulate in chloroplasts. The development of a freezing injury in the acid rain-treated conifer seedlings is discussed in Reinikainen and Huttunen (1989).

\section{Acknowledgments}

This work was supported by the Finnish Ministry of the Environment. Mrs. T. Siltakoski is gratefully acknowledged for her valuable technical assistance.

\section{References}

Davison A.W. \& Barnes J.D. (1986) Effects of winter stress on pollutant responses. In: How are the Effects of Air Pollutants on Agricultural Crops Influenced by the Interaction with Other Limiting Factors. COST-workshop 23-25/3/ 1986. Roskilde. EEC, National Agency of Environmental Pollution, Air Pollution Laboratory

Freer-Smith P.H. \& Mansfield T.A. (1987) The combined effects of low temperature and $\mathrm{SO}_{2}+$ $\mathrm{NO}_{2}$ pollution on the new season's growth and water relations of Picea sitchensis. New Phytol. 106, 237-250

Reinikainen J. \& Huttunen S. (1989) The level of injury and needle ultrastructure of acid rainirrigated pine and spruce seedlings after low temperature treatment. New Phytol. 112, 29-39 